\title{
Evaluation of Neuroprotective Effect of Ficus benghalensis against Alloxan Induced Diabetic Neuropathy in Rats
}

\author{
STALIN C. ${ }^{1, a *}$, GUNASEKARAN V. ${ }^{2, b}$, JAYABALAN G. ${ }^{3, c}$ \\ 1. Research scholar, Sunrise University, Alwar- Rajasthan, India \\ 2. Professor, Dept.of Medicinal Chemistry, Sri Venkateswara College of Pharmacy, \\ Chittoor- Andhra Pradesh, India \\ 3. Professor, Dept. of Pharmacognosy, Alwar College of Pharmacy, Alwar-Rajasthan, India \\ astalinmpharm@gmail.com, ${ }^{b}$ gunasekaran.vedachalam@rediffmail.com, \\ cjeyabalan2011@gmail.com
}

Keywords: Alloxan, Neuroprotective, Ficus benghalensis.

\begin{abstract}
Neuropathic pain in diabetics is characterized by both hyperalgesia and allodynia. This is attributed to both uncontrolled glycemia and the further complications which it leads to. The objective of the study was to evaluate the neuroprotective effect of methanolic leaf extract of Ficus benghalensis against alloxan induced diabetic neuropathy in rats.Experimental diabetes was induced in wistar albino rats by single intraperitoneal injection of Alloxan monohydrate $(150 \mathrm{mg} / \mathrm{kg})$. The methanolic extract of leaves of Ficus benghalensis at a dose of 200 and $400 \mathrm{mg} / \mathrm{kg}$ body weight was administered at single dose per day to diabetes induced rats for a period of 28 days. Neuropathic pain was assessed in diabetic rats with various painful procedures. hot and cold water tail immersion test, pinprick test, cold allodynia, hot plate test, actophotometer and rota-rod tests were performed to assess the degree of thermal, mechanical, cold hyperalgesia and locomotor activity as well as motor co-ordination. Animals treated with methanolic extract of Ficus benghalensis (200, and $400 \mathrm{mg} / \mathrm{kg}$ p.o.) showed good results in different parameters such as thermal allodynia (hot and cold), thermal hyperalgesia and motor co-ordination in comparison with diabetic control group. Thus, from this study we conclude that Ficus benghalensis exhibits significant neuroprotective activities against Alloxan-induced diabetic neuropathy in rats.
\end{abstract}

\section{INTRODUCTION}

Diabetes Mellitus (DM) is defined as a group of metabolic disorders characterized by hyperglycemia, altered metabolism of lipids, carbohydrates and proteins [1]. It is a chronic medical condition that is expected to affect over 300 million people worldwide by 2025[2]. A review of published work on painful diabetic neuropathy suggests that a significant degree of neuropathic pain is more likely to occur in patients with uncontrolled diabetes and has been proposed that acute biochemical alterations in neural tissues might result from prolonged hyperglycemia and could contribute to the development of diabetic neuropathy [3,4]. Four main molecular mechanisms, namely increased polyol pathway flux, increased advanced glycation end- product (AGE) formation, activation of protein kinase $\mathrm{C}(\mathrm{PKC})$ isoforms and increased hexosamine pathway flux have been implicated in glucose-mediated vascular damage and all seems to reflect a single hyperglycemia-induced process of overproduction of superoxide by the mitochondrial electrontransport chain [5]. Clinical and experimental studies have revealed that reactive oxidant species (ROS) play a significant role in pathophysiology of neuropathic pain in diabetes [6]. Adequate metabolic control may reduce the symptoms of painful diabetic neuropathy [7].

Pharmacological agents with proven efficacy for painful diabetic neuropathy include the tricyclic antidepressants, the selective serotonin and noradrenaline reuptake inhibitors, anticonvulsants, opiates, membrane stabilizers, the antioxidant alpha-lipoic acid and topical agents, including capsaicin [8]. The wide variety of medical therapies used to treat diabetic neuropathy attests to the lack of an ideal treatment. Moreover, their use is often associated with problems such as development of adverse side effects, insufficient efficacy and cost-effectiveness. Therefore, 
clinicians looked for other drugs to increase the overall analgesic effect without causing unacceptable side effects [9].

Ficus bengalensis belongs to the family Moraceae, which is commonly known as Banyan tree. Earlier glucoside, 20- tetratriaconthene-2-one, 6-heptatriacontene-10-one, pentatriacontan-5one, beta sitostirolalpha- D-glucose and meso-inositol have been isolated from the bark of Ficus benghalensis [10] Leaves contain crude protein 9.63\%, crude fibres-26.84\%, CaO-2.53\%, and Phosphorus- $0.4 \%$. It yields latex containing Caoytchoue (2.4\%), Resin, Albumin, Cerin, Sugar and Malic acid. It is used in Ayurveda for the treatment of diarrhoea, dysentery and piles [11, 12] teeth disorders [13] Rheumatism, skin disorders like sores [14] to boost immune system [15] as a hypoglycemic [16]. The extracts of Ficus benghalensis were also reported to inhibit insulinase activity from liver and kidney [17].

However, despite of widespread use of Ficus benghalensis as folk medicine to manage DM and other ailments, lack of scientific data on neuroprotective activity against diabetic neuropathy was not been established. Therefore, the present study was designed to evaluate the neuroprotective effects of Methanolic leaf extract Of Ficus Benghalensis against Alloxan Induced Diabetic Rats.

\section{MATERIALS AND METHODS}

\section{Collection and Authentication of Plant:}

The leaves of the tree of Ficus benghalensis were collected from the local areas of Nellore district and authenticated by Dr. Madhava Chetty, Assistant Professor, Dept. of Botany S.V. University - Tirupathi. A portion of the sample was kept in the department museum for future reference.

\section{Chemicals}

All the chemicals used was of analytical grade and procured from Sigma chemicals Co, USA and Qualigens fine chemicals, Mumbai, India.

\section{Animals}

Male Wistar rats weighing 150-220g were obtained from the animal house of Aravind remedies Pvt Ltd. Animals were fed on conventional diets and water ad libitum and they were maintained under standard conditions of humidity, temperature $\left(20-24^{\circ} \mathrm{C}\right)$ and light $(12-\mathrm{h}$ light: $12-$ $\mathrm{h}$ dark cycle).

The rats were randomly assigned to control and different treatment groups, six animals per group. The Institutional Animal Ethics Committee approved the experimental protocol and the conditions in the animal house approved by Committee for Supervision on Experiments on Animals. The study was conducted in accordance with IAEC guidelines (Registration no1696/PO/a/13/CPCSEA/IAEC/22.06.2013). The animals were acclimatized for one week under laboratory conditions.

\section{Induction of Diabetes}

Hyperglycemia was induced by a single i.p. injection of $150 \mathrm{mg} / \mathrm{kg}$ of alloxan monohydrate (Sigma-Aldrich, U.S.A.) in sterile saline solution. Following injecting rats with alloxan by one hour, rats were allowed to be fed standard pellets and water ad libitum ${ }^{[18,19]}$. After that, the experimental rats were administered $20 \%$ glucose solution for 24 hours to prevent hypoglycemia. After $72 \mathrm{hr}$ of Injection, fasting blood glucose level (estimated by glucometer) was measured. Hyperglycemia was confirmed after 5 days of alloxan injection, and hyperglycemic rats (glucose level $>200 \mathrm{mg} / \mathrm{dl}$ ) were separated and selected for the study.

\section{Experimental Design}

Total of 24 diabetic surviving and 6 nondiabetic rats were divided in to 5 groups $(n=6)$ as follows- 


\begin{tabular}{|c|c|}
\hline Group I & Normal rats received only saline $(0.5 \mathrm{~mL} / \mathrm{kg}$ body weight $)$ and served as positive control \\
\hline Group II & $\begin{array}{l}\text { Alloxan diabetic rats that received only vehicles }(0.5 \mathrm{~mL} / \mathrm{kg} \text { body weight) (served as } \\
\text { negative control). }\end{array}$ \\
\hline Group III & $\begin{array}{c}\text { Rats received standard drug Glibenclamide at a dose of } 0.5 \mathrm{mg} / \mathrm{kg} \text { orally for } 28 \text { days }+ \\
\text { a single dose of Alloxan }\end{array}$ \\
\hline Group IV & $\begin{array}{l}\text { Received lower dose of } M E F B 200 \mathrm{mg} / \mathrm{kg} / \mathrm{d} \text { suspended in the vehicle }(10 \mathrm{ml} / \mathrm{kg}) \text { for } 28 \\
\text { days }+ \text { a single dose of Alloxan }\end{array}$ \\
\hline Group V & $\begin{array}{l}\text { Received higher dose of } M E F B(400 \mathrm{mg} / \mathrm{kg} / \mathrm{d} \text { suspended in the vehicle }(10 \mathrm{ml} / \mathrm{kg}) \text { for } \\
28 \text { days }+ \text { a single dose of Alloxan }\end{array}$ \\
\hline
\end{tabular}

During 28 days study period body weight, food and fluid intake of animals were recorded.

\section{EVALUATION OF BEHAVIOURAL ACTIVITY:}

\section{Assessment of hyperalgesia and Allodynia:}

\section{Hot water tail immersion test:}

In hot water tail immersion test, heat hyperalgesia was measured by immersion of terminal part of the tail $(1 \mathrm{~cm})$ in warm water $\left(52.5 \pm 0.5^{\circ} \mathrm{C}\right)$. The duration of tail withdrawal reflex was recorded, as a response of heat thermal sensation and a cut-off time of 15 seconds was maintained. Shortening of tail withdrawal time is an indication for thermal hyperalgesia [20].

\section{Cold water tail immersion test:}

In cold water tail immersion test, distal $5 \mathrm{~cm}$ of tail was immersed in a cold water container by maintaining a constant temperature $\left(10^{\circ} \mathrm{C}\right)$. Duration of time taken for withdrawal of tail from cold water was noted. A cut-off time of $20 \mathrm{sec}$ was maintained to prevent tissue injury. The procedure was repeated three times for each animal and the mean values are taken in consideration. The decrease in tail contact time with cold water was pointing towards nociception, whereas prolonged contact time was noted as anti-allodynic effect [21].

\section{Paw heat- hyperalgesia test (Eddy's hot plate method):}

The nociceptive threshold for heat was an index for thermal hyperalgesia. Eddy's hot plate, which is an instrument designed by Eddy and co-workers to assess thermal sensitivity. The plate was preheated and maintained at a temperature of $52.5 \pm 2.0^{\circ} \mathrm{C}$. The rat was placed on the hot plate and nociceptive threshold, with respect to licking of the hind paw or jumping, was recorded in seconds. The cut-off time of $20 \mathrm{sec}$ was maintained [21].

\section{Mechanical hyperalgesia (Pin prick test):}

According to Erichsen and Blackburn-Munro, the surface of the injured hind paw was touched with a point of the bent gauge needle at $90^{\circ}$, without piercing deep into tissue. The intensity was sufficient to produce a reflex withdrawal response in normal control animals. The duration of the paw withdrawal was recorded in seconds using $20 \mathrm{sec}$ as cut-off time [21].

\section{Cold hyperalgesia (Acetone drop test):}

Cold chemical thermal sensitivity was assessed using acetone drop method as described by Choi $\mathrm{Y}^{[22]}$ with modification. Rats were placed in a metal mesh cage and allowed to habituate for approximately 20 minutes in order to acclimatise them for the new environment. Freshly dispensed acetone drop $(50 \mu \mathrm{L})$ was applied gently on to the mid plantar surface of the hind paw. It generates a cold chemical sensitive reaction i.e., paw licking, shaking or rubbing the hind paw with brisk foot withdrawal after application $(2-5 \mathrm{sec})$ of acetone was considered as nociceptive response and absence or delay in these responses were considered as anti-nociceptive effect. Each test was repeated three times with 5 min interval between each application of acetone on both paws and mean was calculated. 


\section{Motor coordination:}

The test was conducted with Rota rod apparatus (Scientec, India), by placing rats on $25 \mathrm{rpm}$ rotating spindle. The falling time of each rat from rotating spindle was recorded during five minutes period [23].

\section{Spontaneous Locomotor (Exploratory) Test:}

Photoactometer test was engaged to assess the spontaneous motor (exploratory) behaviour of the rodents with actophotometer (Scientec, India). Each animal was observed for a period of 5 min in a square closed field area $(30 \times 30 \times 30 \mathrm{~cm})$ equipped with 6 photocells in the outer wall. Interruptions of photocell beam (locomotor/exploratory action) of rats were recorded by digital counter $[6,24]$.

\section{Statistics}

Data obtained in the experiment were expressed in terms of mean \pm SEM. Statistical significance of data was assessed by analysis of variance (one-way ANOVA) followed by a comparison between different groups using "Dunnet" test. The significance level was set at $\mathrm{P}<0.05$.

\section{RESULTS:}

\section{Effect of Ficus benghalensis on behavioural parameters:}

\section{Hot and cold water tail immersion test:}

Alloxan induced hyperglycaemia results in progressive heat hyperalgesia and cold allodynia which was showed by the shortening of tail withdrawal latency in comparison with normal rats. MEFB treated rats started to show early significant improvement in tail withdrawal latency at dose $400 \mathrm{mg} / \mathrm{kg}$ from $14^{\text {th }}$ day and $200 \mathrm{mg} / \mathrm{kg}$ showed the effect on $21^{\text {st }}$ day for hot water tail immersion test (Table-1). In cold water tail immersion both the doses 200 and $400 \mathrm{mg} / \mathrm{kg}$ significantly improved tail withdrawal latency in a dose dependent manner. (Table-2).

\section{Paw heat- hyperalgesia test:}

Alloxan induced Diabetic rats showed significant reduction in paw withdrawal latency when compared with normal rats (group 1). Standard drug Glibenclamide at a dose of $0.5 \mathrm{mg} / \mathrm{kg}$ significantly $(\mathrm{P}<0.001)$ improved the paw withdrawal latency from $14^{\text {th }}$ day. Whereas 200 and $400 \mathrm{mg} / \mathrm{kg}$ of MEFB significantly $(\mathrm{P}<0.05)$ improved the paw withdrawal latency from $21^{\text {st }}$ day in comparison with diseased control rats (Table-3).

\section{Pinprick test:}

In pinprick test the hyper responsiveness to a noxious stimulus was observed with significant rise in paw withdrawal latency in diabetic control as compared with normal control. Whereas, treatment with 200 and $400 \mathrm{mg} / \mathrm{kg}$ of MEFB caused significant reduction in paw withdrawal latency in a dose dependent manner. The anti-nococeptive effect of MEFB was found similar effective to the reference standard Glibenclamide (Table- 4).

\section{Acetone drop test:}

In this test, applying acetone on plantar surface of hyperglycemic rats resulted in cold allodynia, it was indicated by the raised paw withdrawal duration than the normal control. Animals treated with MEFB $400 \mathrm{mg} / \mathrm{kg}$ was given significant $(\mathrm{P}<0.05)$ results from the $14^{\text {th }}$ day whereas 200 $\mathrm{mg} / \mathrm{kg}$ were started to show reduction in paw withdrawal latency from $21^{\text {st }}$ day as compared to disease control (group 2). Standard drug Glibenclamide significantly $(\mathrm{P}<0.001)$ decreased the paw withdrawal latency from the 14th day (Table-5). 


\section{Motor coordination and locomotor activity:}

Rats treated with MEFB showed significant improvement in muscle grip strength and locomotor activity as compared with disease control. Improvement in motor coordination activity was achieved with the dose of 200 and $400 \mathrm{mg} / \mathrm{kg}$ from $14^{\text {th }}$ day respectively (Table-6,7).

\section{Body weight, food intake and water intake}

Body weight of Alloxan induced diabetic control rats was found to be significantly $(p<0.05)$ less compared to normal control rats. After 4 weeks of treatment with MEFB body weight significantly $(\mathrm{p}<0.05)$ increased compared to diabetic control groups. Food intake was significantly high in diabetic control rats as compared to normal control. At the end of 28 days of treatment food intake of treated groups significantly $(p<0.01)$ decreased as compared to diabetic control. Significant decrease $(\mathrm{p}<0.01)$ in water intake was observed in treated groups as compared to diabetic control at the end of study period. (Table: 8 ).

Table 1: Effect of MEFB on rats subjected to hot water tail immersion test.

\begin{tabular}{|l|c|c|c|c|c|}
\hline \multirow{2}{*}{ Treatment } & \multicolumn{5}{|c|}{ Reaction time (Sec) } \\
\cline { 2 - 6 } & Day 1 & Day 7 & Day 14 & Day 21 & Day 28 \\
\hline Group I & $10.67 \pm$ & $10.42 \pm 1.021$ & $10.54 \pm 0.622$ & $10.94 \pm 0.612$ & $11.02 \pm 0.092$ \\
\hline Group II & $5.82 \pm 0.621$ & $5.69 \pm 1.049$ & $5.43 \pm 1.021$ & $5.32 \pm 1.169$ & $5.16 \pm 0.42$ \\
\hline Group III & $5.32 \pm 0.753$ & $6.85 \pm 1.169$ & $8.36 \pm 0.42 * * *$ & $11.60 \pm 0.516^{* * *}$ & $13.12 \pm 0.92^{* * *}$ \\
\hline Group IV & $5.17 \pm 0.07$ & $5.68 \pm 0.516$ & $6.56 \pm 0.432$ & $7.56 \pm 0.146^{* *}$ & $8.16 \pm 0.640^{* * *}$ \\
\hline Group V & $5.26 \pm 1.062$ & $6.32 \pm 0.753$ & $7.54 \pm 0.642^{* * *}$ & $9.76 \pm 0.091^{* * *}$ & $12.02 \pm 1.211^{* * *}$ \\
\hline
\end{tabular}

All values are presented as Mean $\pm \mathrm{SD},(\mathrm{n}=6), \mathrm{p}<0.05^{*}, \mathrm{p}<0.01^{* *}, \mathrm{p}<0.001^{* * *}$ when compared to disease group.

Table 2: Effect of MEFB on rats subjected to cold water tail immersion test

\begin{tabular}{|l|c|c|c|c|c|}
\hline \multirow{2}{*}{ Treatment } & \multicolumn{5}{|c|}{ Reaction time (Sec) } \\
\cline { 2 - 6 } & Day 1 & Day 7 & Day 14 & Day 21 & Day 28 \\
\hline Group I & $12.83 \pm 0.548$ & $12.13 \pm 0.753$ & $12.91 \pm 0.548$ & $12.17 \pm 0.523$ & $12.5 \pm 0.348$ \\
\hline Group II & $6.96 \pm 0.491$ & $6.16 \pm 0.324$ & $5.72 \pm 0.516$ & $4.98 \pm 0.548$ & $4.69 \pm 0.814$ \\
\hline Group III & $6.52 \pm 0.684$ & $7.36 \pm 1.004$ & $9.66 \pm 1.302^{* * *}$ & $12.84 \pm 0.653 * * *$ & $14.64 \pm 0.464 * * *$ \\
\hline Group IV & $6.42 \pm 0.766$ & $6.88 \pm 0.686$ & $7.62 \pm 0.753^{* *}$ & $8.36 \pm 0.516^{* * *}$ & $9.42 \pm 0.548^{* * *}$ \\
\hline Group V & $6.61 \pm 0.620$ & $7.14 \pm 0.296$ & $9.16 \pm 0.436^{* * *}$ & $11.14 \pm 0.622^{* * *}$ & $12.48 \pm 0.532^{* * *}$ \\
\hline
\end{tabular}

Table 3: Effect of MEFB on rats subjected to paw heat- hyperalgesia test

\begin{tabular}{|l|c|c|c|c|c|}
\hline \multirow{2}{*}{ Treatment } & \multicolumn{5}{|c|}{ Reaction time (Sec) } \\
\cline { 2 - 6 } & Day 1 & Day 7 & Day 14 & Day 21 & Day 28 \\
\hline Group I & $11.82 \pm 0.04$ & $11.36 \pm 0.24$ & $11.42 \pm 0.16$ & $11.72 \pm 0.34$ & $11.86 \pm 0.472$ \\
\hline Group II & $6.78 \pm 1.032$ & $6.04 \pm 1.062$ & $5.96 \pm 0.824$ & $4.91 \pm 0.632$ & $5.13 \pm 0.516$ \\
\hline Group III & $5.92 \pm 0.216$ & $6.39 \pm 0.472$ & $8.21 \pm 1.042^{* * *}$ & $11.68 \pm 0.824^{* * *}$ & $13.38 \pm 1.002^{* * *}$ \\
\hline Group IV & $6.12 \pm 0.612$ & $7.02 \pm 0.049$ & $7.56 \pm 0.734$ & $8.96 \pm 0.216^{* * *}$ & $10.26 \pm 0.816^{* * *}$ \\
\hline Group V & $5.72 \pm 0.046$ & $6.36 \pm 2.032$ & $7.84 \pm 1.021$ & $10.24 \pm 1.024 * * *$ & $11.34 \pm 1.014^{* * *}$ \\
\hline
\end{tabular}

All values are presented as Mean $\pm \mathrm{SD},(\mathrm{n}=6), \mathrm{p}<0.05^{*}, \mathrm{p}<0.01^{* *} \mathrm{p}<0.001^{* * *}$ when compared to disease group. 
Table 4: Effect of MEFB on rats subjected to pinprick test

\begin{tabular}{|l|c|c|c|c|c|}
\hline \multirow{2}{*}{ Treatment } & \multicolumn{5}{|c|}{ Reaction time (Sec) } \\
\cline { 2 - 6 } & Day 1 & Day 7 & Day 14 & Day 21 & Day 28 \\
\hline Group I & $2.03 \pm 0.682$ & $2.11 \pm 1.402$ & $2.14 \pm 0.516$ & $2.18 \pm 0.140$ & $2.01 \pm 0.166$ \\
\hline Group II & $11.36 \pm 1.036$ & $12.03 \pm 1.052$ & $12.96 \pm 1.402$ & $13.93 \pm 0.872$ & $14.86 \pm 1.204$ \\
\hline Group III & $11.86 \pm 1.169$ & $10.02 \pm 2.026$ & $9.17 \pm 1.472 * * *$ & $6.83 \pm 1.472 * * *$ & $5.36 \pm 1.032 * * *$ \\
\hline Group IV & $11.54 \pm 0.604$ & $10.64 \pm 0.247$ & $10.14 \pm 0.738^{* *}$ & $8.50 \pm 1.049 * * *$ & $8.05 \pm 0.633 * * *$ \\
\hline Group V & $11.34 \pm 1.006$ & $10.96 \pm 1.246$ & $9.83 \pm 0.983 * * *$ & $8.41 \pm 1.038 * * *$ & $6.81 \pm 0.462 * * *$ \\
\hline
\end{tabular}

All values are presented as Mean $\pm S D,(n=6), p<0.05^{*}, p<0.01^{* *}, p<0.001^{* * *}$ when compared to disease group.

Table 5: Effect of MEFB on rats subjected to acetone drop test

\begin{tabular}{|l|c|c|c|l|c|}
\hline \multirow{2}{*}{ Treatment } & \multicolumn{5}{|c|}{ Reaction time (Sec) } \\
\cline { 2 - 6 } & \multicolumn{1}{|c|}{ Day 1 } & \multicolumn{1}{|c|}{ Day 7 } & \multicolumn{1}{c|}{ Day 14 } & \multicolumn{1}{c|}{ Day 21 } & Day 28 \\
\hline Group I & $6.32 \pm 0.0302$ & $6.06 \pm 0.418$ & $6.26 \pm 0.564$ & $6.45 \pm 0.432$ & $6.16 \pm 0.466$ \\
\hline Group II & $28.16 \pm 2.471$ & $31.12 \pm 2.514$ & $32.74 \pm 1.926$ & $35.18 \pm 1.842$ & $33.14 \pm 2.032$ \\
\hline Group III & $27.62 \pm 4.012$ & $25.31 \pm 2.148$ & $20.24 \pm 3.468^{* * *}$ & $14.74 \pm 2.456^{* * *}$ & $11.36 \pm 2.030$ \\
\hline Group IV & $28.76 \pm 4.062$ & $26.18 \pm 1.368$ & $24.12 \pm 3.248$ & $21.74 \pm 3.062^{* * *}$ & $17.17 \pm 2.542^{* * *}$ \\
\hline Group V & $28.42 \pm 4.182$ & $24.33 \pm 2.034$ & $22.83 \pm 3.068^{* *}$ & $17.94 \pm 2.542^{* * *}$ & $14.96 \pm 2.164 * * *$ \\
\hline
\end{tabular}

All values are presented as Mean $\pm \operatorname{SD},(n=6), p<0.05^{*}, p<0.01^{* *}, p<0.001^{* * *}$ when compared to disease group.

Table 6: Effect of MEFB on rats subjected to motor co-ordination test (Rota-rod)

\begin{tabular}{|l|l|l|l|l|l|}
\hline \multirow{2}{*}{ Treatment } & \multicolumn{5}{|c|}{ Reaction time (Sec) } \\
\cline { 2 - 6 } & \multicolumn{1}{|c|}{ Day 1 } & \multicolumn{1}{|c|}{ Day 7 } & \multicolumn{1}{c|}{ Day 14 } & \multicolumn{1}{c|}{ Day 21 } & \multicolumn{1}{c|}{ Day 28 } \\
\hline Group I & $128.65 \pm$ & $129.2 \pm 7.134$ & $128.33 \pm 5.611$ & $128.52 \pm 6.062$ & $129.34 \pm 6.074$ \\
\hline Group II & $48.67 \pm 6.036$ & $52.16 \pm 5.062$ & $58.67 \pm 6.968$ & $64.54 \pm 5.764$ & $67.32 \pm 6.064$ \\
\hline Group III & $56.50 \pm 6.014$ & $69.43 \pm 5.186$ & $84.34 \pm 5.005^{* * *}$ & $102.62 \pm 5.377^{* * *}$ & $112.17 \pm 4.572^{* * *}$ \\
\hline Group IV & $57.68 \pm 6.564$ & $61.34 \pm 6.268$ & $68.63 \pm 6.697$ & $78.83 \pm 6.796^{* *}$ & $84.17 \pm 6.768^{* * *}$ \\
\hline Group V & $57.17 \pm 6.494$ & $63.82 \pm 6.636$ & $75.52 \pm 7.428^{* *}$ & $86.02 \pm 8.210^{* * *}$ & $95.50 \pm 5.321^{* * *}$ \\
\hline
\end{tabular}

All values are presented as Mean $\pm \operatorname{SD},(n=6), p<0.05^{*}, p<0.01^{* *}, p<0.001^{* * *}$ when compared to disease group.

Table 7: Effect of MEFB on rats subjected to locomotor activity test (Actophotometer)

\begin{tabular}{|l|l|l|l|l|l|}
\hline \multirow{2}{*}{ Treatment } & \multicolumn{5}{|c|}{ Reaction time (Sec) } \\
\cline { 2 - 6 } & \multicolumn{1}{|c|}{ Day 1 } & \multicolumn{1}{|c|}{ Day 7 } & \multicolumn{1}{c|}{ Day 14 } & \multicolumn{1}{c|}{ Day 21 } & \multicolumn{1}{c|}{ Day 28 } \\
\hline Group I & $122.50 \pm 8.744$ & $121.83 \pm 7.452$ & $123.68 \pm 11.692$ & $122.83 \pm 8.565$ & $121.33 \pm 9.501$ \\
\hline Group II & $36.33 \pm 7.236$ & $38.98 \pm 5.324$ & $38.17 \pm 6.882$ & $39.56 \pm 6.584$ & $42.33 \pm 6.784$ \\
\hline Group III & $38.17 \pm 6.492$ & $58.26 \pm 5.262$ & $52.67 \pm 6.250^{* * *}$ & $64.83 \pm 6.314 * * *$ & $72.17 \pm 5.168^{* * *}$ \\
\hline Group IV & $39.14 \pm 8.565$ & $48.22 \pm 6.253$ & $46.33 \pm 7.324$ & $50.86 \pm 6.556^{* *}$ & $54.17 \pm 7.242^{* *}$ \\
\hline Group V & $35.67 \pm 6.022$ & $49.24 \pm 8.377$ & $47.63 \pm 5.457$ & $56.16 \pm 5.610^{* *}$ & $65.34 \pm 6.064 * * *$ \\
\hline
\end{tabular}

All values are presented as Mean $\pm \mathrm{SD},(\mathrm{n}=6), \mathrm{p}<0.05^{*}, \mathrm{p}<0.01^{* *}, \mathrm{p}<0.001^{* * *}$ when compared to disease 
Table 8: Effect of MEFB on body weight, food and water intake in Alloxan diabetic rats

\begin{tabular}{|c|c|c|c|c|c|c|}
\hline $\begin{array}{c}\text { Experiment } \\
\text { Groups }\end{array}$ & \multicolumn{3}{|c|}{ Body weight (g) } & \multicolumn{2}{c|}{ Food intake (g/24 hrs) } & \multicolumn{2}{c|}{$\begin{array}{c}\text { Water intake } \\
\text { (ml/24hrs) }\end{array}$} \\
\hline Group I & Initial & Final & Initial & Final & Initial & Final \\
\cline { 2 - 7 } & $189.16 \pm 8.78$ & $197 \pm 8.45$ & $14.5 \pm 0.77$ & $18.08 \pm 1.08$ & $11 \pm 0.38$ & $11.16 \pm 0.35$ \\
\hline Group II & $183.16 \pm 7.11$ & $139.16 \pm 4.527$ & $21 \pm 1.75$ & $29.75 \pm 1.24$ & $44.33 \pm 3.19$ & $75 \pm 3.84$ \\
\hline Group III & $164.33 \pm 5.42$ & $168.16 \pm 7.46$ & $18.33 \pm 0.90$ & $16.5 \pm 0.70$ & $48.33 \pm 0.90$ & $16.5 \pm 0.70$ \\
\hline Group IV & $164.33 \pm 6.76$ & $183.16 \pm 6.405$ & $26.33 \pm 1.815$ & $16.83 \pm 0.97$ & $58.83 \pm 4.62$ & $34.25 \pm 1.59$ \\
\hline Group V & $195.16 \pm 5.05$ & $201.33 \pm 3.12$ & $31.66 \pm 2.24$ & $18.66 \pm 1.02$ & $52.16 \pm 2.15$ & $19.66 \pm 1.45$ \\
\hline
\end{tabular}

\section{Discussion}

A strong relationship exixts between glycemia and diabetic microvascular complications in both type 1 and type 2 diabetes [5]. Generation of superoxide due to oxidative stress in diabetes may be responsible for vascular and neuronal complications of painful neuropathy [6]. Alloxan is a cyclic urea compound, which induces permanent diabetes. It is a highly reactive molecule, which produces free radical damage to beta islet cells \& causes cell death. When islets are exposed in vitro to alloxan, it exhibits exceptional beta cell specificity, the other islets cells remaining largely unaffected by both its inhibitory and cytotoxic effects. Alloxan is a specific toxic substance that destroys the $\beta$ cells provoking a state of primary deficiency of insulin without affecting other islet types $[24,25]$. The damage occurs in nerves, hence, alloxan was selected to induce diabetes in the present study.

In this study methanolic leaf extract of Ficus benghalensis was given for the prevention as well as treatment of neuropathic pain in Alloxan induced diabetic rats. The development of neuropathy was observed at $7^{\text {th }}$ day after induction of diabetes, which was consistent with previous reports $[6,26]$.

The behavioural parameters such as thermal and cold hyperalgesia; and allodynia was assessed by using hotplate, pin prick, acetone drop test, and hot and cold water tail immersion tests along with motor coordination as well as locomotor activity.

In behavioural examination, diabetic rats were shown significant reduction in tail and paw withdrawal latency than the normal control rats, is an indication for decreased nociceptive threshold to heat resulting hyperalgesia and allodynia. Similar models of thermal hyperalgesia and tail flick latency have been reported previously in Alloxan induced diabetic animals. The delay in tail withdrawal response depicts the involvement of spinal reflex arc and delay in paw withdrawal latencies to noxious thermal stimuli depicts the involvement of supra spinal sensory pathways.

The hyperalgesic response to a noxious stimulus (pin prick) and development of cold chemical sensitivity in diabetic rats were shown significant rise in hind paw withdrawal latency than the normal rats. It has been reported that involvement of TRPA1 and ATP-gated purinergic ionchannel P2X3 may be responsible for mechanical hyperalgesia.

Rats treated with 200 and $400 \mathrm{mg} / \mathrm{kg}$ were shown improvement in muscle grip strength at $14^{\text {th }}$ and $28^{\text {th }}$ day respectively. At the same time a progress in locomotor activity was also observed. This indicates its protective role against damage to the neurons.

\section{Acknowledgments}

The authors are thankful to the Management and Plant head, Aravind Remedies Pvt ltd for providing the facilities to carry out this study. The authors are also thankful to Mr.R.Murugan, Mr.C.Mohan and Mrs. Lakshmi Prasanna Stalin for their help during the project work. 


\section{Conclusions}

The results reveals that oral administration of Methanolic extract of Ficus benghalensis leaves not only attenuated the Alloxan induced diabetic condition but also reversed the neuropathic pain. The probable mechanism could be via enhancing insulin production and decreasing the glucagon production. The onset of neuropathic complications could be prevented by early glycemic controls. Thus, from this study we conclude that Ficus benghalensis exhibits significant neuroprotective activities against Alloxan-induced diabetic neuropathy in rats. However, further studies are required for the better understanding of the mechanism of action.

\section{References}

[1] L. Packer, K. Kraemer, G. Rimbach, Molecular aspects of lipoic acid in the prevention of diabetes complications, Nutrition 17 (2001) 888-895.

[2] M. Farswan, P.M. Mazumder, V. Percha, Protective effect of Cassia glauca Linn. On the serum glucose and hepatic enzymes level in streptozotocin induced NIDDM in rats, Indian J. Pharmacol. 41 (2009) 19-22.

[3] J.H. Lee, D.J. Cox, D.G. Mook, R.C. McCarty, Effect of hyperglycemia on pain threshold in alloxan-diabetic rats, Pain. 40 (1990) 105-107.

[4] J. Kastrup et al., Intravenous lidocaine infusion - a new treatment of chronic painful diabetic neuropathy?, Pain. 28 (1987) 69-75.

[5] M. Brownlee, Biochemistry and molecular cell biology of diabetic complications, Nature. 414(6865) (2001) 813-820.

[6] M. Anjaneyulu, K. Chopra, Quercetin attenuated thermal hyperalgesia and cold allodynia in STZ-induced diabetic rats, Indian Journal of Experimental Biology. 42 (2004) 766-769.

[7] J. Kastrup et al., Intravenous lidocaine infusion - a new treatment of chronic painful diabetic neuropathy?, Pain. 28 (1987) 69-75.

[8] Tesfaye et al., Painful diabetic peripheral neuropathy: Consensus recommendations on diagnosis, assessment and management, Diabetes Metabol. Res. Rev. 27 (2011) 629-638.

[9] S.O. Kim, H.J. Kim, Berberine ameliorates cold and mechanical allodynia in a rat model of diabetic neuropathy, J. Med. Food. 16 (2013: 511-517.

[10] P.M. Subramanian, G.S. Misra, Chemical constituents of Ficus benghalensis, Polish Journal of Pharmacology and Pharmacy. 30 (4) (1978) 559-562.

[11] P.K. Mukherjee et al., Screening of antidiarrhoeal profile of some plant extracts of a specific region of West Bengal, India, Journal of Ethnopharmacology. 60 (1) (1998) 85-89.

[12] A. Husain et al., Dictionary of Indian Medicinal Plants, CIMAP, Lucknow, India, 1992.

[13] M.N. Aiyer, A.N. Namboodiri, M. Kolammal, Pharmacognosy of Ayurvedic drugs, Trivandrum 1957.

[14] P.K. Warrier, VPK Nambiar, C. Ramankutty, Indian Medicinal Plants, (1-5) Orient Longman Ltd., Madras, 1995.

[15] S.Y. Gabhe, P.A. Tatke, T.A. Khan, Evaluation of the immunomodulatory activity of the methanol extract of Ficus benghalensis roots in rats, Indian Journal of Pharmacology. 38 (4) (2006) 271-275.

[16] K.T. Augusti, Hypoglycemic action of bengalenoside, a glucoside isolated from Ficus benghalensis Linn, in normal and alloxan diabetic rabbits, Indian Journal of Physiology and Pharmacology. 19(4) (1975) 218-220.

[17] S. Achrekar, G.S. Kaklij, M.S. Pote, S.M. Kelkar, Hypoglycemic activity of Eugenia jambolana and Ficus benghalensis: mechanism of action, In Vivo. 5(2) (1994) 143-147.

[18] S. Ghosh, S.A. Suryawanshi, Effect of Vinca rosea extract in treatment of alloxan diabetes in male albino rats, Indian J. Expt. Biol. 39 ( 2001) 748-759.

[19] C.R. Reshmi, A. Fatima, B. Sinilal, MS Latha, Antidiabetic effect of herbal drug in Alloxan diabetic rats, Indian Drugs. 38 (2001) 319-322. 
[20] N. Attal, F. Jazat, V. Kayser, G. Guilbaud, Further evidence for pain-related behaviours in a model of unilateral peripheral mononeuropathy. Pain. 41 (1990) 235-251.

[21] S.A. Kanaan et al., Endotoxin-induced local inflammation and hyperalgesia in rats and mice: A new model for inflammatory pain, Pain. 66 (1996) 373-379.

[22] Y. Choi et al., Behavioral signs of ongoing pain and cold allodynia in a rat model of neuropathic pain, Pain. 59 (1995) 369-376.

[23] R.J. Carter, J. Morton, S.B. Dunnett, Motor coordination and balance in rodents, Curr Protoc Neurosci. (2001) 8-12.

[24] A. Kar, B.K. Choudhary, N.G. Bandyopadhyay, Comparative evaluation of hypoglycemic activity of some Indian medicinal plants in alloxan diabetic rats, J. Ethnopharmacol. 84 (2003) 105108.

[25] E.N.M. Claudia, E.O. Julius, T. Dagobert, D. Etienne, Antidiabetic and Hypolipidemiceffects of Laporteaovalifolia (URTICACEAE) in alloxan induced diabeticrats, Afr. J. Tradit. Complement. Altern. Med. 3(1) (2006) 36-43.

[26] B. Aubel et al., Antihyperalgesic effects of cizolirtine in diabetic rats: behavioral and biochemical studies, Pain. 110 (2004) 22-32. 